\title{
Reflexões sobre o futuro do ensino profissionalizante nas áreas técnicas do espetáculo ao vivo no Brasil
}

\author{
Laura Maria de Figueiredo
}

\begin{abstract}
Resumo
O artigo traz alguns dados sobre a realidade do mercado de trabalho nas áreas técnicas dos espetáculos ao vivo no Brasil, notadamente nas artes cênicas: teatro e shows de música, a partir do marco histórico que foi a Lei 6.533/78, que institui oficialmente a profissão no Brasil. Atualmente tais áreas são vistas como um campo fecundo para criação de cursos técnicos de nível médio, com grande potencial de empregabilidade na atual "sociedade do espetáculo", conforme o conceito de Guy Debord. O texto procura trazer parâmetros de economia da cultura e sociologia da educação para levantar questóes sobre os modelos de referências para a criação de propostas curriculares e percursos formativos nesta área de ensino profissionalizante, que precisam viabilizar a sobrevivência da profissão e dos profissionais da área, e não apenas atender às demandas de um campo de trabalho já precário e vulnerável pelas políticas neoliberais em vigor.
\end{abstract}

Palavras chave: Ensino Profissionalizante. Técnicos cênicos. Espetáculos ao vivo.

\begin{abstract}
The article brings some data about the reality of the labor market in the technical areas of the live shows in Brazil, notably in the performing arts: theater and music shows, from the historical boundary that was the law $6.533 / 78$, which officially established the career in Brazil. At present these areas are seen as a fruitful field for the creation of technical courses, with great potential of employability in the present "society of the spectacle", according to the concept of Guy Debord. The text attempts to search parameters of cultural economics and sociology of education to introduce questions about the models of references for the creation of curricular proposals and training courses in this area of vocational education, which need to enable the survival of the profession and professionals in the area, and not only meet the demands of a labor camp that is already precarious and vulnerable by the current neoliberal policies.
\end{abstract}

Keywords: Vocational Teaching. Performing Arts Techinics. Live Shows.

\footnotetext{
${ }^{I}$ Mestre em Artes pelo Programa de pós-graduação em Artes Cênicas da Escola de Comunicações e Artes da Universidade de São Paulo e Licenciada em Teatro pela mesma instituição. Professora Assistente no Centro de Ciências Humanas Letras e Artes da UFRN, Departamento de Artes, Curso de Licenciatura em Teatro. E-mail: <llaufigueiredo@gmail.com>
} 
Quando o público vê um espetáculo em cena, não imagina o grande número de profissionais do palco que concorre para a apresentação teatral, [...] pouca gente sabe que um certo detalhe do cenário, o modo de preparar um adereço, um efeito de luz aparentemente insignificante são o resultado de pesquisa, estudo, concentração e experiência. [...] Há na verdade um segundo espetáculo que o público não vê, e cuja açẫo tem lugar nas coxias do teatro, no quadro de luz, nas varandas do palco, na cabine de projeçáo e de sonoplastia para que tudo aconteça numa corrida contra o relógio, a fim de que Sua Excelência O Público possa ver a peça fluir tranquilamente, sem que tenha a impressão de nenhum esforço. [...] Eles são os técnicos do teatro. E entretanto o público não lhes guarda o nome, [...], os críticos raramente lhes dedicam uma linha. [...] E, sem eles, o teatro náo vive. Desde que na antiga tragédia grega inventou-se o deus-ex-machina, foi um técnico teatral que encontrou a solução. E a partir daí, eles têm caminhado juntos com a evolução do teatro. Em uma de suas peças mais famosas Ibsen se pergunta quem são Os Pilares da Sociedade? No nosso caso não há dúvida, os pilares do teatro são os técnicos.

Flávio Rangel² "ANTES QUE O PANO SUBA”, 1975.

\section{Introdução}

O texto de Flávio Rangel transcrito acima revela a importância da contribuição laboral dos técnicos em espetáculos ao vivo de um modo geral e não apenas no Teatro. A história do trabalho técnico nas áreas do espetáculo ao vivo no Brasil atravessou o século XX espelhando, as contradiçóes do desenvolvimento do país e de suas artes cênicas nos seus aspectos políticos e econômicos. Esse trabalhador que executa um ofício simultaneamente braçal e técnico, mas também poético, já que lida com esferas de códigos e linguagens estéticas, só começou a ganhar status de membro da equipe, a partir dos anos 1950, ganhando créditos nominais nos programas teatrais ${ }^{3}$ geralmente como eletricista ou maquinista. Até então só constava a divulgação dos nomes de estrelas, galās, divas, vedetes, e os nomes das suas Companhias produtoras de espetáculos. Posteriormente nos anos 1970 passam a figurar outros tipos de créditos: iluminador, sonoplasta, cenotécnico entre outros. Flávio Rangel escreveu num programa de teatro da época esse texto que destacamos na epígrafe.

No Brasil contemporâneo, ancorados em diversos modelos de políticas culturais, de incremento da produção e popularização da fruição de bens culturais como mercadoria (Adorno, Horkheimer, 1997); esses ofícios pertencem ao segmento de atividade denominado Economia da Cultura (BENHAMOU, 1997) por alguns analistas, ou de Economia Criativa por organizaçóes internacionais (British Council, Banco Mundi-

\footnotetext{
${ }^{2}$ Flávio Rangel (1934 - 1988) Dramaturgo e Encenador de Teatro brasileiro. Vale notar que também é chamado de Diretor de Teatro em grande parte das vezes, com suas interessantes implicações sociais e profissionais a partir das distinções semânticas para nominar esse ofício no mundo do teatro.

${ }^{3}$ Programas são os cadernos ou folhetos, vendidos ou distribuídos ao público que assiste a um espetáculo onde são descritos os ofícios envolvidos (artísticos e técnicos) e o nome de seus respectivos executores.
} 
al $)^{4}$, mas em comum temos : 1) a realidade do ambiente sócio-econômico-politico neoliberal que aprofundou o mundo do trabalho vulnerável. (Singer, 2006; Antunes, 2009); 2) a atratividade que a Sociedade do Espetáculo (Debord, 1997), confere a essas atividades econômicas; 3) o uso de tecnologias de ponta aliadas às diversas linguagens artísticas envolvidas na prática profissional de trabalhadores dessas áreas.

Neste momento os técnicos de espetáculos brasileiros se capacitam para a profissão aprendendo na medida das necessidades que a vida prática lhes apresenta, na troca com outros profissionais e/ou com graus variados de autodidatismo, e/ou investimentos pessoais em cursos particulares. Ainda é pouquíssimo o acesso a conhecimentos sistematizados e abrangentes sobre suas áreas de atuaçáo, através de cursos regulamentados. Esses fatores trazem para o debate sobre os currículos de formação na área alguns aspectos relevantes que analiso a seguir.

\section{A profissão no Brasil - breve relato histórico}

Tardiamente, dentro da esfera de consolidação dos direitos trabalhistas na legislação brasileira, iniciada na década de 1930, a profissão de técnico em espetáculos só foi devidamente reconhecida em 1978 pela Lei 6.533/78 e regulamentada pelo decreto 82.385/78, juntamente com as disposiçóes sobre a profissão de artistas cênicos (atores, bailarinos, artistas circenses), e de técnico de espetáculos (técnicos de luz, som, cenotécnica, contra regra, maquinista, camareira). Trata-se de profissóes complementares entre si reunindo os trabalhadores técnicos e artistas, das áreas de cultura (popular e erudita), lazer e entretenimento ao vivo 5 .

Esta conquista histórica viu, em rápidos quinze anos depois, o esfacelamento de seus direitos trabalhistas garantidos pela CLT brasileira, através do processo de precarização do contexto econômico e social do trabalhador ocasionados pelas políticas neoliberais, e seu rolo compressor atuante sob a égide da flexibilizaçáo das relaçôes entre capital e trabalho, durante os dois mandatos de Fernando Henrique Cardoso na Presidência da República. (1994-2002). Na pratica do 'mercado'6 de trabalho a legislação trabalhista desde entâo passou a vigorar somente para técnicos empregados pelas emissoras de TV, radio e espaços culturais institucionais, enquanto que essa legislação foi rapidamente revogada por grande parte dos empresários da área, na prática das contrataçôes temporárias para a realização dos espetáculos, tanto para os/as técnicos, como para os/as artistas. Soma-se a isso a conivência de uma categoria profissional desmobilizada, com fraca representatividade através de seus sindicatos e alienada dos conhecimentos de seus direitos trabalhistas. $\mathrm{Ou}$ seja, em grande parte deste segmento vigora há cerca de 20 anos a informalidade, que passou a ser combatida por conta da sonegação fiscal que imperava, através da inclusão dessas categorias no sistema do Micro Empreendedor Individual ${ }^{7}$.

Concomitante a isso o avanço das atividades culturais e de lazer nos setores produtivos da economia brasileira através das leis de incentivos fiscais ${ }^{8}$, ou contemplados com recursos do Ministério da Cultura, fez crescer a demanda de trabalhadores para atuação técnica nos espetáculos em números

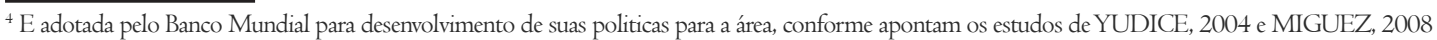

${ }^{5}$ As descrições das funções técnicas do espetáculo ao vivo contidas na lei estão defasadas com as práticas profissionais atuais, pois as intensas transformações tecnológicas pelas quais passaram essas áreas com a cultura digital, trouxeram novas ocupações e postos de trabalhos no segmento de atuação. Urge uma revisão das profissões relativas ao setor dentro do $\mathrm{CBO}$.

6 Coloco entre aspas a palavra mercado pois defendo a seguir como ela é inadequada no Brasil para caracterizar a práxis profissional na área.

${ }^{7}$ Toda a temeridade que parte das organizações trabalhadoras apontam para o tema da transformação do trabalho em mercadoria através 'pejotizacao' do trabalhador pelo PL4330, derrotado em 2004, mas que voltou a tramitar no Congresso Brasileiro em 2015, já vigora há anos neste segmento com terríveis malefícios para a categoria, os quais poderão ser abordados em outro texto.

${ }^{8}$ Lei Rouanet e suas correlatas em Estados e Municípios do país. Os produtores culturais contemplados com esses benefícios são os principais contratantes que aviltam os direitos trabalhistas dessa categoria.
} 
exponenciais, visando atender a intensa agenda das salas de espetáculos, centros culturais, grupos de teatro ou dança e todo o tipo de eventos e shows ao vivo. Aumentando consideravelmente o 'campo de trabalho’ na área9 .

Segundo dados divulgados pelo IBGE, e utilizados pelo $\mathrm{MinC}^{10}$ para avaliar suas políticas para a chamada economia da cultura, as empresas culturais são responsáveis por $5 \%$ dos postos de trabalho no Brasil, e os serviços culturais, nas quais a demanda pelos trabalhos técnicos se acentua, perfaz 9\% dos postos de trabalho, remunerando em média com 5,9 salários mínimos, enquanto em outros setores de serviço a média salarial é de 3,2 mínimos. Trata-se de um setor da cadeia produtiva em permanente expansão, necessitando de trabalhadores qualificados.

Neste contexto que poderia ser chamado de promissor sob a ótica das possiblidades de inserçấo social e econômica, não fossem os problemas inerentes ao mundo do trabalho no ambiente neoliberal, impóe-se a necessidade da criação de cursos extensivos - 800 horas, com grade curricular elaborada para configurar propostas de certificação oficializadas para esta área, dentro do ensino profissionalizante brasileiro. A urgência desse tipo de controle da atuação profissional nas artes cênicas brasileiras envolve duas faces de um mesmo problema: de um lado a criação de cursos credenciados pelo MEC, e de outro a certificação regulamentada e obrigatória para o exercício da profissáo.

Como exemplo extremo das consequências perversas da realidade brasileira neste segmento de atividade, entregue ao laissez faire de um mercado desregulamentado ${ }^{11}$, temos os acontecimentos da Boate Kiss em Santa Maria que mostraram, entre outros elementos que se somaram para a ocorrência da tragédia, o despreparo dos técnicos e dos artistas do show da banda naquela noite ${ }^{12}$. O episódio desolador reúne aspectos exemplares dos graves problemas que assolam o ambiente profissional desta área no Brasil, representados pelos empresários inescrupulosos na busca por altos lucros com mínimos custos, pelos artistas alienados e trabalhadores técnicos mal preparados atuando por baixa remuneração, e carentes, entre tantas outras deficiências na sua formação, de conhecimentos sobre segurança, prevenção e controle de acidentes e sinistros. E, coroando o panorama critico, temos a falta de regulamentaçáo e fiscalização do poder público em diversos âmbitos dessas atividades da economia da cultura e do lazer.

\section{A formação profissional em seu estágio atual}

Durante praticamente todo o século XX a formação deste técnico de montagens de espetáculos, nas áreas de som, luz e cenotécnica, era feita na relação entre mestre e aprendiz, quando os profissionais veteranos ensinavam os mais jovens no cotidiano do trabalho, ou através de cursos livres e oficinas ministradas por profissionais. Porém, o sempre crescente 'mercado de trabalho' na área, necessita de tantos trabalhadores, que esse tipo de formação já não dá conta de suprir.

\footnotetext{
${ }^{9}$ Não chamo de mercado de trabalho, porque, em tese dentro do Capitalismo moderno, um mercado é regido por leis, minimamente regulamentado e fiscalizado pelo Estado. No Brasil, ao contrário esse setor de atividade está totalmente entregue ao desamparo da lei e da fiscalização como já mencionado, e onde o exercício profissional está exposto às piores consequências para o trabalhador, dos conflitos de interesses entre Capital X Trabalho dentro da economia capitalista.

10 "Sistema de Informações e Indicadores Culturais 2007-2010" IBGE/MinC, 2006. Disponível em: <ibge.gov.br>. Acesso em: 7 jul. 2015.

${ }^{11}$ A mais plena realização das aspirações neoliberais para o Mercado.

${ }^{12}$ Incêndio acontecido em 27/0I/2013 durante a apresentação da banda Gurizada Fandangueira na boate Kiss em Santa Maria/RS, que matou 242 pessoas, na maioria jovens universitários que realizavam uma festa/balada. Foi apurado nas investigações o uso inadequado de um efeito pirotécnico (sputinik), que só pode ser utilizado em eventos ao ar livre e que detonou a tragédia quando foi aceso durante o show por um integrante da banda.
} 
Vale salientar que na atualidade o ensino técnico nesta área é valorizado para o cacife das carteiras de competências, habilidades, e empregabilidade no curto prazo do horizonte dos cursos profissionalizantes brasileiros em suas concepções neoliberais ${ }^{13}$ por conta de seu apelo dentro do escopo de interesses dos jovens e pelo já citado estímulo econômico que representam essas atividades no atual estágio do sistema capitalista.

O Parecer n. ${ }^{0} 11 / 2008$, que institui o Catálogo Nacional de Cursos Técnicos ${ }^{14}$ define as profissões que se enquadram sob a rubrica de produção cultural e design:

Compreende tecnologias relacionadas com representaçóes, linguagens, códigos e projetos de produtos, mobilizadas de forma articulada às diferentes propostas comunicativas aplicadas. Abrange atividades de criação, desenvolvimento, produção, edição, difusão, conservação e gerenciamento de bens culturais e materiais, idéias e entretenimento, podendo configurar-se em multimeios, objetos artísticos, rádio, televisão, cinema, teatro, ateliês, editoras, vídeo, fotografia, publicidade e nos projetos de produtos industriais. Tais atividades exigem criatividade e inovação com critérios sócio-éticos, culturais e ambientais, otimizando os aspectos estético, formal, semântico e funcional, adequando-os aos conceitos de expressão, informação e comunicação, em sintonia com o mercado e as necessidades do usuário. $\mathrm{Na}$ organizaçấo curricular dos cursos desse eixo, ética, raciocínio lógico, raciocínio estético, empreendedorismo, normas técnicas e Educação Ambiental são componentes fundamentais na formação de técnicos que atuam em equipes com iniciativa, criatividade e sociabilidade (BRASIL/MEC, 2008, p.6).

Excessivamente genérico o parecer coloca tudo no mesmo padrão: tecnologia, criação de objetos com design, linguagens, representaçôes, cultura, comunicação, teatro, rádio, diversos outros meios e mídias que, se existir alguma faceta que possa reuni-las, talvez fosse o critério: utilizam na sua operacionalidade equipamentos eletroeletrônicos. Além disso, enfatiza que os conhecimentos envolvidos para o exercício profissional dessas atividades devam ser construídos "adequando-os aos conceitos de expressão, informação e comunicação, em sintonia com o mercado e as necessidades do usuário." [grifo autor]. Com relação ao currículo sugere eixos: "ética, raciocínio lógico, raciocínio estético, empreendedorismo, normas técnicas e Educação Ambiental são componentes fundamentais na formação de técnicos que atuam em equipes com iniciativa, criatividade e sociabilidade." (BRASIL/MEC, 2008, p.6).

O texto acima que serve de parâmetro para a criação de formatos curriculares para a profissionalização nesses ofícios, denota desconhecimento sobre a realidade brasileira das profissóes, dos seus contextos de desenvolvimentos e de postos de trabalhos, que se desenvolvem em áreas muito distintas entre si e que criam identidades diversas, principalmente em países em desenvolvimento, como o Brasil, porém com forte dependência econômica dos centros de poder tecnológicos do mundo globalizado. O que se percebe neste Parecer é o uso referencial dos parâmetros alinhavados pelos trabalhos realizados por estudiosos do mundo anglo-saxão, e que passaram a nortear o escopo de atividades que envolvem a chamada Economia Criativa, como apontou Paulo Miguez,

${ }^{13}$ Nesse viés de concepção de ensino profissionalizante destaca-se a SP Escola de Artes do Palco, escola municipal planejada na gestão de José Serra e do PSDB no Estado; e executada com ligeireza burocrática espantosa, que incluiu a fundação de uma OnG, (Amigos da Praça), para o estabelecimento de uma parceria público) privada, porém construída com amplos recursos orçamentários do Estado, para inauguração durante a campanha eleitoral para Presidência da República em 2009. I4 BRASIL - “Catálogo Nacional de Cursos Técnicos de Nível Médio” MEC PARECER CNE/CEB Nº:II/2008. 
[...] nos últimos dez anos, o campo da economia da cultura tem vindo a defrontar-se com a possibilidade de um novo deslocamento por força de uma novidade que, emergindo do mundo anglófono, já desfruta de visibilidade e acolhimento por parte de instituiçôes multilaterais e, também, de outros países. Trata-se da noção de economia criativa posta em marcha, na metade dos anos 1990, pelos governos Britânico e Australiano. Desde então, estes dois países têm acionado um conjunto específico de políticas voltadas para potencializar atividades que, embora marcadamente culturais, foram por eles denominadas de indústrias criativas (MIGUEZ,2008, p. 9).

Estes são os estudos econômicos para o setor ${ }^{15}$ que organizaçóes multilaterais se utilizam atualmente: Unesco, Banco Mundial, BID e outros, para pensar estratégias e políticas de desenvolvimento econômicos. Destaco no Parecer a ênfase na adequaçáo aos interesses deste mercado, e seu ponto de vista sobre o que são os temas gerais de conhecimentos necessários para a produção de mercadorias culturais.

A influência das diretrizes do Banco Mundial nos projetos educacionais brasileiros, como destaca o estudo de Rosa Maria Torres, apresentam fragilidades e contradiçóes no campo prático:

O BM afirma que seu papel é colocar ao alcance dos países em desenvolvimento um cardápio de opçôes de política para que estes selecionem a combinação mais adequada a suas necessidades. No entanto, o pacote do BM é essencialmente um pacote homogeneizador e prescritivo. Isso aliado muitas vezes a uma recepção isenta de crítica por parte das contrapartidas nacionais e dos países beneficiários dos empréstimos, resulta na adoção de enfoques, políticas, programas e projetos similares em todo o mundo, inclusive em realidades muito diferentes. Embora o BM recomende adaptação e flexibilidade, nem todos os seus técnicos têm a capacidade para aceita-las ou promove-las responsavelmente entre seus assessorados em cada país (TORRES, 1998, p. 179).

Portanto, são esses ideários e espectros conceituais que serviram de parâmetros para a elaboração do PARECER CNE/CEB no:11/2008. Ao assimilar as profissões técnicas, que são executoras de projetos artísticos em suas formalizaçôes tecnológicas e materiais, no mesmo patamar das profissões artísticas que geram propriedade intelectual, o Parecer denota mais uma vez seu vínculo com a chamada indústria criativa, e ignora as diferenças oriundas das naturezas das práticas profissionais, problemas que seria evitado se houvesse consultoria de trabalhadores das áreas.

Mas o futuro do ensino profissionalizante nas áreas técnicas dos espetáculos ao vivo terá de se confrontar com outros exemplos pedagógicos, entranhados na nossa tradição de ensino profissional, o chamado Sistema S, representado pelas escolas e cursos promovidos por entidades empresariais: SENAC, SESI, SENAI.

\footnotetext{
${ }^{15}$ As indústrias criativas são conceituadas como "indústrias que têm sua origem na criatividade, habilidade e talento individuais e que têm um potencial para geração de empregos e riquezas por meio da geração e exploração da propriedade intelectual. Isto inclui propaganda, arquitetura, o mercado de artes e antiguidades, artesanatos, design, design de moda, filme e vídeo, software de lazer interativo, música, artes cênicas, publicações, software e jogos de computador, televisão e rádio" (BRITISH COUNCIL, 2005. p.5 apud MIGUEZ, 2008, p. 9).
} 


\section{A teoria do capital humano e o ensino profissionalizante no Brasil}

Outro modelo determinante para o desenvolvimento de projetos educacionais profissionais no mundo capitalista foi construído a partir a Teoria do Capital Humano desenvolvida por Schultz ${ }^{16}$, e que avalia a relação entre educação e trabalho a partir de investimentos em educação formal e/ou especializada, realizadas como investimento do Estado, ou pelos sujeitos sociais individualmente, para o desenvolvimento de seu potencial de produtividade, empregabilidade e remuneração. Tal teoria impregnou a literatura que se desenvolveu desde os anos 1970 sob a rubrica de Recursos Humanos, para nortear investimentos em qualificação para o trabalho e para produção dentro dos moldes capitalistas. Em relação ao ensino técnico profissionalizante tais teorias desaguaram no chamado Modelo de Competências, e sua práxis para a construçáo de programas político-pedagógicos. Esses modelos e pontos de vistas estão amplamente disseminados nos formatos curriculares de ensino profissionalizantes brasileiros presentes no Sistema $\mathrm{S}$.

Autores brasileiros (FRIGOTTO, 1993; RAMOS, 2002) apontaram as bases ideológicas embutidas na Teoria do Capital Humano, e no chamado modelo de competências, que vigora nos debates sobre o ensino profissionalizante adotado no país. Como demonstrou Deluiz,

[...] a reforma educacional implementada no Brasil a partir da Lei 9394/96 (LDB) e, a seguir, nos dispositivos de regulamentação no que se refere à educação profissional, como o Decreto-Lei 2208/9717 e as Diretrizes Curriculares Nacionais para a Educaçáo Profissional, consubstanciadas no Parecer CNE/CEB no 16/99, na Resolução CNE/CEB no 04/9919 e nos Referenciais Curriculares Nacionais para a Educação Profissional, assumem como concepção orientadora o modelo das competências (DELUIZ, 2001, p.4).

A autora demonstra a gênese desse conceito no mundo empresarial e seu alinhamento com a visão de reduzir o conceito de recursos humanos às suas estratégias e seus modelos taylorista-fordista de gerenciar pessoas:

As novas concepçôes gerenciais que surgem no bojo desse processo recomposição da hegemonia capitalista e das relaçôes capital-trabalho e têm como objetivos racionalizar, otimizar e adequar a força de trabalho face às demandas do sistema produtivo (DELUIZ, 2001, p. 1).

As implicaçôes contraditórias decorrentes desta visão do modelo de competência que mascara valores individuais (talento, criatividade) através de sua assimilação aos resultados, ou seja, o trabalhador competente faz uso destes dotes num esforço consciente de afirmar seu comprometimento com os interesses do capital:

No modelo das competências o controle da força de trabalho se expressa através de estratégias de ressocialização e aculturação pela conformação da subjetividade do trabalhador. A ênfase na identificação dos interesses de patrôes e empregados - que se convertem em uma comunidade social de colaboradores -; a autogestáo pela internalização da disciplina; o controle exercido sobre os trabalhadores por

${ }^{16}$ SCHULT, T. O Capital Humano: investimento em educação e pesquisa. Trad. de Marco Aurélio de M. Matos, Rio de Janeiro, Zahar, I973. 
seus próprios colegas no trabalho em equipe e a sobrevalorizaçáo de aspectos atitudinais (o saber-ser) conferem ao modelo das competências a possibilidade de um controle menos formalizado e mais difuso sobre a força de trabalho, evitando-se as resistências e os conflitos (DELUIZ, 2001, p. 2).

Nos atuais parâmetros ideológicos que norteiam o pensamento sobre recursos humanos que tem sua matriz na Teoria do Capital Humano, e seus desdobramentos nas práticas educacionais e de treinamento para trabalhadores, sempre aparecem as palavras: iniciativa, criatividade e sociabilidade. Na mencionada capacidade de trabalhar em equipe, aparecem as competências individuais, subjetivas em suas manifestaçóes, mas muito claras sob o foco do interesse do capital como demonstra Deluiz acima; e presentes em quaisquer perfil do profissional ideal na atualidade, mesmo que tal espirito de equipe seja estraçalhado pela lógica da competição por postos de trabalhos e remuneração, que no caso das profissóes técnicas do espetáculo ao vivo, acontecem num campo de trabalho sem garantias e sem lei como vimos antes.

Outro conceito indispensável no jargão do Modelo das Competências é o Empreendedorismo, cujo espectro ideológico reforça a típica atitude que se espera de um /uma jovem pronto para 'vencer' na vida, como se valores do mundo corporativo capitalista pudessem ser naturalizados no ambiente do ensino de todas as profissóes, ou como se o acesso a esse patamar profissional seja simplesmente uma questão de horas/aula, e/ou aspiração pessoal de qualquer sujeito social, tornando irrelevantes todas as limitaçôes geradas por diversos níveis de exclusão e vulnerabilidade social que permeiam nossa sociedade desigual e o universo da educação dentro dela.

\section{Considerações finais}

Nesta década e meia de século XXI as artes cênicas brasileiras em seus aspectos sócio-econômico-políticos se encontram em uma encruzilhada histórica importante no que concerne a novos panoramas sobre as áreas profissionais que precisam ser cobertas por ensino especializado e regulamentador, coisa que ocorreu com as áreas de atuação, encenação e ensino do teatro como linguagem artística, que vieram no bojo da regulamentação da profissão no final dos anos 1970. Neste momento se faz necessário a construção de projetos político-pedagógicos para outras áreas de atividades relacionadas a esse segmento profissional, com foco nas atividades técnicas e artísticas do chamado, no jargão profissional globalizado, backstage.

É provável que a construção dos currículos formativos dos cursos que serão instalados no Brasil seja idealizada sobre esses modelos em vigor, pois como se sabe o MEC estabeleceu parcerias com o Sistema S e, portanto seguirão as bases teóricas mostradas neste trabalho: Teoria do Capital Humano; Modelo de Competências e Economia Criativa; com todas as consequências ideológicas implicadas na formação dessas categorias profissionais. Ficam algumas perguntas cruciais: Como os/as profissionais da área vão interagir com essas diretrizes? Como transformar esses profissionais técnicos em educadores? Como viabilizar uma carreira profissional digna através desta regulamentação? Como garantir que a profissão não se degrade ainda mais, se continuar entregue a esse modelo de competitividade predadora do mercado neoliberal? Faz-se necessário criar uma crítica contundente para desconstruir esse enfoque 
da educação apenas pelo fator econômico e que aliena concepçóes políticas, sociais, filosóficas e éticas, subordinando-as aos interesses de mercado da produção capitalista, pois como analisa Frigotto, na lógica da Teoria do Capital Humano:

[...] o que interessa do ponto de vista educativo, não é o que interessa do ponto de vista dos que se educam, mas do mercado. Neste contexto o ato educativo, definido como uma prática eminentemente política e social, fica reduzido a uma tecnologia educacional (FRIGOTTO, 1993, p. 67).

Outro aspecto relevante para construção da massa crítica sobre o tema é considerar que no modelo de educação profissionalizante neoliberal, a ênfase dos percursos formativos recai nos aspectos tecnológicos, que se sobrepóem aos de práticas poéticas e artísticas, que correm o risco de ser negligenciadas ou fracamente abordadas nos formatos curriculares, bem como os temas de Humanidades que favoreçam o despertar do senso crítico do trabalhador para a realidade sócio-econômico-política de exploração, na qual construirá sua carreira profissional.

Os desafios colocados para a construção dos currículos para a formação técnica e artística na área de espetáculos ao vivo que, por ser, num horizonte mais amplo, a política pública que irá estabelecer alguns dos pilares para o futuro dessa atividade cultural e econômica no Brasil, deverá atender às mais legítimas necessidades de uma categoria profissional de trabalhadores, sua tradição e identidades, e não só ao ideário de competência propostos pelos interesses da cultura do showbussines do mercado de trabalho neoliberal.

\section{Referências}

ADORNO, Theodor; HORKHEIMER, Max. Dialética do esclarecimento: fragmentos filosóficos. 6.reimp. Rio de Janeiro: Zahar, 1997.

ANTUNES, Ricardo. Os modos de ser da informalidade: rumo à uma nova era de precarização estrutural do trabalho? Serv. Soc. Soc., São Paulo, n. 107, p. 405-419, jul./set. 2011.

BENHAMOU, Françoise. La economia de la cultura. Montevideo: Trilce, 1997.

BRASIL. Catálogo Nacional de Cursos Técnicos de Nível Médio. MEC PARECER CNE/CEB No:11/2008.

DEBORD, Guy. A sociedade do espetáculo. Rio de Janeiro: Contraponto, 1997.

DELUIZ, Neise. $\mathbf{O}$ modelo das competências profissionais no mundo do trabalho e na educaçáo: implicaçôes para o currículo. Boletim técnico do SENAC, 2001.

FRIGOTTO, Gaudêncio. A produtividade da escola improdutiva. 4.ed. São Paulo: Cortez, 1993. p.35-67. 
IBGE/MinC. Sistema de Informaçóes e Indicadores Culturais 2007-2010. Disponível em: <www.ibge. gov.br>. Acesso em: 07 jul. 2015.

MIGUEZ, Paulo. Alguns aspetos do processo de constituiçáo do campo de estudos em economia da cultura. IV Enecult, 2008, Faculdade de Comunicação/UFBA, 2008.

RAMOS, Marise. Pedagogia das Competências: autonomia ou adaptação? São Paulo: Ed. Cortez, 2002.

SINGER, Paul. Globalizaçáo e Desemprego: diagnóstico e alternativas. 4. ed. São Paulo: Ed. Contexto, 2006.

TORRES, Rosa Maria. Melhorar a qualidade da educação básica? As estratégias do Banco Mundial. In: TOMMASI, Lívia, Warde, Jorge Mirian, Haddad, Sérgio. (Orgs.). O Banco Mundial e as políticas Educacionais. São Paulo: Cortez, 1998.

YÚDICE, George. A conveniência da cultura - usos da cultura na era global. Belo Horizonte, UFMG, 2004. 